ISTH

The 2011 State of the Art Book

\title{
Natural history of Upshaw-Schulman syndrome based on ADAMTS13 gene analysis in Japan
}

\author{
Y. FUJIMURA*, M. MATSUMOTO*, A. ISONISHI*, H. YAGI*, \\ K. KOKAME†, K. SOEJIMA $\ddagger$ M. MURATA§, T. MIYATA $†$, \\ *Department of Blood Transfusion Medicine, Nara Medical University, Nara, Japan \\ †Department of Molecular Pathogenesis, National Cerebral and Cardiovascular \\ Center, Suita, Osaka, Japan \\ $\ddagger$ The First Research Department, The Chemo-Sero-Therapeutic Research Institute, \\ Kumamoto, Japan \\ §Department of Laboratory Medicine, Keio University School of Medicine, Tokyo, \\ Japan
}

Running head: Natural history of Upshaw-Schulman syndrome

Correspondence: Yoshihiro Fujimura, Department of Blood Transfusion Medicine, Nara Medical University, 840 Shijo-cho, Kashihara City, Nara, 634-8522, Japan. Tel:+81-744-22-3051 (Ext 3289), Fax: +81-744-29-0771, E-mail: malon@naramed-u.ac.jp 


\section{Abbreviation}

ADAMTS13 (a disintegrin-like and metalloprote--ase with thrombospondin type 1 motifs 13)

aHUS (atypical hemolytic uremic syndrome)

CAPD (continuous ambulatory peritoneal dialysis)

CR-TTP (chronic relapsing thrombotic thrombocytopenic purpura)

DCM (disease-causing muation)

DDAVP (1-desamino-8-D-arginine vasopressin)

DIC (disseminated intravascular coagulation)

FFP (fresh frozen plasma)

HELLP (hemolysis, elevated liver-enzymes, low platelets)

ITP (idiopathic thrombocytopenic purpura)

MAHA (microangiopathic hemolytic anemia)

SNP (single nucleotide polymorphism)

SLE (systemic lupus erythematosus)

TMA (thrombotic microangiopathies)

TTP (thrombotic thrombocytopenic purpura)

UL-VWFM (unusually large von Willebrand factor multimers)

VWF-CP (von Willebrand factor-cleaving protease)

USS (Upshaw-Schulman syndrome) 


\section{Summary}

Upshaw-Schulman syndrome (USS) is an extremely rare hereditary deficiency of ADAMTS13 activity, termed congenital TTP. The clinical signs are usually mild during childhood, often the isolated thrombocytopenia. But their symptoms become evident when the patients have infections or get pregnant. We identified 43 USS-patients in Japan, who ranged in age from early childhood to 79 years old. Analyzing the natural history of these USS patients based on ADAMTS13 gene mutations may characterize their clinical phenotypes.

Severe neonatal jaundice that requires exchange blood transfusion, a hallmark of USS, was found in 18 of 43 patients (42\%). During childhood, 25 of 43 patients were correctly diagnosed of USS without gender disparity. These 25 patients were categorized as having "the early-onset phenotype". Between 15 and 45 years of age, 15 were correctly diagnosed, and interestingly they were all female. The remaining three patients were all male and were diagnosed when they got older than 45 years of age, suggesting that they were "the late-onset phenotype". Two of these 3 males developed sudden overt TTP when they were 55 and 63 years old. These two men had two different homozygous ADAMTS13 gene mutations, p.R193W/p.R193W and p.C1024R/p.C1024R, respectively. Both of which were not discovered in the US and Western countries. In vitro expression studies showed that these two proteins were consistently secreted into the culture medium but to a lesser extent and with reduced activity compared to the wild-type protein. Our results indicate that "the late-onset phenotype” of USS is formed with ethnic specificity.

Keywords; Upshaw-Schulman syndrome, ADAMTS13 gene mutation, natural history, clinical phenotype 


\section{Introduction}

Upshaw-Schulman syndrome (USS) is a hereditary deficiency in the activity of von Willebrand factor-cleaving protease (VWF-CP) [1], termed ADAMTS13 (a disintegrin-like and metalloprotease with thrombospondin type 1 motifs 13) [2-4]. In the absence of ADAMTS13, unusually large VWF multimers (UL-VWFMs) released from vascular endothelial cells are inappropriately cleaved, which induce platelet hyperagglutination under high shear stress [5]. Thus, USS is alternatively called congenital thrombotic thrombocytopenic purpura (TTP). On the other hand, approximately half of congenital atypical hemolytic uremic syndrome (aHUS) cases are caused by genetic mutations in complement regulatory factors, such as factor $\mathrm{H}, \mathrm{I}$, and $\mathrm{B}$, and membrane cofactor protein, or thrombomodulin [6]. However, the majority of both TTP and HUS occur in the acquired form, and it has been said that TTP and HUS patients predominantly exhibit neurotropic and nephrotropic signs, respectively. Further, it is often difficult to discriminate between these two diseases in clinical practice [7-9] because both diseases are identified based on common pathological features termed thrombotic microangiopathies (TMAs), which are characterized by organ dysfunction due to platelet thrombi in the microvasculature, consumptive thrombocytopenia, and microangiopathic hemolytic anemia (MAHA) [10].

The classic hallmarks of USS are severe neonatal jaundice with a negative Coombs test that requires an exchange blood transfusion and repeated childhood episodes of thrombocytopenia and MAHA that are reversed by infusions of fresh frozen plasma (FFP) [11]. However, recent studies indicated that the clinical signs of USS during childhood may be much milder than expected, and often an isolated thrombocytopenia occurs, causing physicians to sometimes overlook this important disease [12].

Despite a lengthy history on clinical diagnoses of USS, only 10 years have passed since the disease-related enzyme, ADAMTS13, was discovered [3, 4, 13, 14]. Furthermore, USS is an extremely rare disease, and to date, it is estimated that there have been approximately 100 patients worldwide [15]. In this regard, Nara Medical University has functioned as a TMA referral center in Japan since 1998 and collected a large dataset of 919 patients with TMA between 1998-2008 [16]. In this registry, we identified 41 USS patients in 36 different families who ranged in age from early 
childhood to 79 years old. Subsequently, until the end of March 2011, we have identified 2 new USS-patients belonged to different families in Japan. Analyzing the natural history of these 43 USS-patients will further our understanding of the clinical significance of ADAMTS13, which functions to regulate the size of platelet-thrombi that form in the microvasculature under high shear stress.

\section{Historical backgrounds}

In 1953, Dacie et al. [17] reviewed 12 patients with atypical congenital hemolytic anemia and identified a 6-year-old girl who had experienced repeated episodes of severe jaundice, thrombocytopenia, hemolytic anemia, and schistocytes since she was a newborn. Before first visiting Dacie, this patient had received a splenectomy but did not improve. She died of renal failure at 7 years of age. This patient was the third of four children, and both the first and second children were jaundiced at birth and died of hemorrhage at 2 years and 4 days old, respectively. The fourth child and the parents were asymptomatic. Thus, the authors concluded that these 3 patients must have a hitherto unrecognized hereditable blood disease.

In the absence of any known concept of TTP, in 1960, Schulman et al. [18] reported an 8-year-old girl who had no coagulation abnormalities but repeated bleeding episodes due to chronic thrombocytopenia and MAHA. These symptoms dramatically improved with fresh plasma infusions, suggested that the patient had a congenital deficiency in a "platelet-stimulating factor" in her plasma. In 1978, Upshaw [19] reported the case of a 29-year-old female who had repeated episodes of thrombocytopenia and MAHA starting in childhood and was successfully treated with plasma infusions. Of note, both Schulman and Upshaw determined that plasma infusions successfully treated their patients. Rennard and Abe [20] reported a case that was originally identified by Upshaw with "a slightly decreased level of plasma cold-insoluble globulin (fibronectin) during the acute phase”, and proposed a nomenclature of USS for these types of patients. However, no correlation between the fibronectin levels and disease activity in USS patients was reported by Koizumi et al. [21] and Goodnough et al. [22], including Schulman's original case. Furthermore, after the thrombopoietin assay was established, Miura et al. [23] reported 5 Japanese USS patients with a normal plasma level of thrombopoietin. 
Thus, all the pathogenic features that were initially postulated for USS have been entirely excluded by subsequent investigations.

For this reason, the term USS was almost forgotten in 1997, when the assay for VWF-CP (now ADAMTS13) activity was established. Instead, the practical diagnostic term of 'chronic relapsing TTP (CR-TTP)' has been historically used. This term was coined by Moake et al. [24], who found that UL-VWFMs were present in the plasma of 4 CR-TTP patients including the Upshaw's case during the remission phase, but disappeared during the acute phase. In 1997, Furlan et al. [25] showed that 4 CR-TTP patients, who were distinct from the cases of Moake et al. [24], lacked VWF-CP activity, but did not examine the presence of ADAMTS13 inhibitors. However, it was retrospectively determined that 2 CR-TTP patients in both the case reports by Moake et al. [24] and Furlan et al. [25] had congenital TTP, while the remaining 2 cases in each report had acquired TTP. Under these circumstances, we re-visited the term USS [11], which included analyzing 3 Japanese patients with USS, and found that they uniformly had a severe deficiency in VWF-CP activity (determined based on the VWFM assay in the presence of $1.5 \mathrm{~mol} / \mathrm{L}$ urea) and no evidence of inhibitors. The parents of these patients were asymptomatic and had moderately decreased VWF-CP activity (17-60\% of normal), except for one carrier who had very low VWF-CP activity (5.6\% of normal). Later, this carrier was shown to have a unique single nucleotide polymorphism (SNP), a p.P475S mutation in the ADAMTS13 gene in one allele, which is very common among Japanese people (9.6\% of normal individuals are heterozygous for the p.P475S mutation) [26].

In 2001, Levy et al. provided solid evidence that linked congenital TTP or USS and ADAMTS13 gene mutations [3], and simultaneously other research groups successfully purified this enzyme and/or cloned the encoding cDNA [2, 4, 13, 14].

\section{Patients, Materials and Methods}

\section{USS patients}

Forty-three USS patients (28 females and 15 males) belonging to 38 different families and their family members were enrolled in this study.

\section{Assays for plasma ADAMTS13 activity and ADAMTS13 inhibitors}


Between 1998 and 2004, our laboratory examined ADAMTS13 activity using a classic VWFM assay in the presence of $1.5 \mathrm{~mol} / \mathrm{L}$ urea following the method of Furlan et al. [27]. The detection limit of this assay was 3\% of the normal control [11]. In 2005, Kato et al. [28] developed a novel chromogenic ADAMTS13-act-ELISA using a recombinant VWF substrate (termed GST-VWF73-His). The detection limit of this assay was $0.5 \%$ of the normal control [28]. Both assays had a high correlation, and since then, the VWFM assay was completely replaced with the act-ELISA. In our patients with USS, the ADAMTS13 activity was determined at least 2 different occasions, using their plasmas obtained at more than 2 weeks after the last plasma infusion therapy. Further, In some experiments with normal individuals as described below, FRETS-VWF73 assays [29] were used.

The ADAMTS13 inhibitor titers were evaluated using the Bethesda method, and the values less than 0.5 Bethesda $U(B U) / m L$ were negative, but those between 0.5 $-1.0 \mathrm{BU} / \mathrm{ml}$ were assumed to be marginal.

\section{Assay for IgG-type plasma ADAMTS13 binding antibody titers}

Measurement of plasma anti-ADAMTS13 IgG antibody titers in USS-patients was performed by means of Ferrari et al. [30] with a slight modification as the followings. Briefly, the recombinant (r) ADAMTS13 was directly coated to micro-titer plates, and after blocking with Protein-Free Blocking Buffers (PIERCE, Rockford, IL), the coated plates were incubated with normal and patient plasma dilutions. The IgG-type antibody bound to rADAMTS13 was detected by using horseradish peroxidase-conjugated goat anti-human IgG (AbD Serotec, Kidlington, UK) with a TMB substrate kit (Thermo Scientific, Rockford, USA) at absorbance $450 \mathrm{~nm}$ at room temperature for $15 \mathrm{~min}$. The results were calculated as a ratio of sample OD at each dilution divided by normal plasma OD at each dilution. The IgG antibody titer of a sample corresponds to the last dilution at which the ratio is above the cut-off level. This assay kit was kindly provided from Drs. Barbara Plaimauer and Friedlich Scheiflinger of Baxter BioScience. In our laboratory, 25 normal plasmas (15 males and 10 males, aged between 20 and 40 years) consistently showed the titer of IgG-type binding antibody with a less than 25-fold dilution (shown as $<25 \mathrm{X}$ in Table 1). 


\section{ADAMTS13 gene analysis}

All DNA analyses of the ADAMTS13 gene were performed as previously described [26], with permission from the Ethics Committees of both the sample-collecting hospitals and the institute that performed the gene analysis. Hereafter, the disease-causing muations (DCMs) of ADAMTS13 will be written in bold letters.

\section{Results}

\section{ADAMTS13 SNPs among Japanese individuals}

The human ADAMTS13 gene is located on chromosome 9q34. The gene consists of 29 exons, and the translated enzyme contains 1427 amino acid residues with a multi-domain structure $[2,4]$. To date, more than 10 SNPs in ADAMTS13 have been identified worldwide [3, 26]. Among these, Japanese people $(n=3616)$ had six SNPs with the following allele frequencies, respectively: p.T339R (exon 9) (2.7\%), p.Q448E (exon 12) (19.2\%), p.P475S (exon 12) (5.0\%), p.P618A (exon 16) (2.7\%), p.S903L (exon 21) (4.8\%), and p.G1181R (exon 25). (2.2\%) [31]. Both p.T339R and p.P618A are almost completely linked in the general Japanese population, but this linkage may not exist in the Caucasian population as some reports have described individuals carrying p.P618A but not p.T339R [32, 33]. Plasma and rADAMTS13 with the Asian-specific SNP, p.P475S [26, 34, 35], has markedly reduced activity compared to the wild-type protein in both the VWFM assay in the presence of urea (1.5 mol/L) [26] and the FRETS-VWF73 assay in the absence of urea [36], although the contribution of this polymorphism to thrombotic diseases has not been determined.

Recently, we have analyzed the nucleotide sequences of ADAMTS13 in 128 individuals without a history of TTP and identified 14 rare nonsynonymous mutations. Interestingly, among these 14 mutations, three mutations of p.I673F (exon 17), p.Q723K (exon 18), and c.3220del TACC, were also found as DCMs for USS in this study (below). Thus, the remaining 11 mutations may or may not be associated with a reduced activity of plasma ADAMTS13 [31].

\section{Natural history of 43 USS-patients in Japan}


Until the end of March 2011, we identified 43 USS patients in 38 different families (Family USS-A LL) who ranged in age from early childhood to 79 years old. Hence, we present an up-dated natural history of these 43 USS patients together with their family members (Tables 1 and 2).

\section{Family USS-A}

Patient: One male (USS-A4) born in 1999

Brief clinical data: The history of USS-A4 (ADAMTS13 genotype: p.R268P /p.Q448E-p.C508Y) before he reached 5 years of age was previously described [11, 26 , 37]. He currently receives biweekly of FFP infusions $(10 \mathrm{~mL} / \mathrm{kg} \mathrm{BW})$ that are prepared from several fixed donors to prevent allergic reactions. He contracted the seasonal influenza A virus in 2010 and became severely ill with a reduced platelet count but did not develop overt TTP. He is currently in good clinical condition and has not had signs of renal or hepatic dysfunction. Both of his parents are asymptomatic carriers, but his father, aged 45 years old, has a p.R268P/p.P475S genotype and very low plasma ADAMTS13 activity at $5.6 \%$ of normal by the VWFM assay in the presence of $1.5 \mathrm{~mol} / \mathrm{L}$ urea [26] and 3.6\% by the chromogenic ADAMTS13-act-ELISA in the absence of urea (unpublished data).

\section{Family USS-B}

Patient: One female (USS-B3) born in 1986

Brief clinical data: USS-B3 (ADAMTS13 genotype: p.Q449X/p.Q449X) is an only child who was born in Hokkaido to non-consanguineous parents. Her history prior to reaching 5 years of age was previously described [11, 26, 38]. Since childhood, she has received prophylactic FFP infusions. As a consequence, she was infected with hepatitis $\mathrm{C}$ and has received interferon therapy on two different occasions. In both instances, accelerated thrombocytopenia was observed despite the regular prophylactic FFP infusions. Furthermore, during her early childhood, she received DDAVP (1-desamino-8-D-arginine vasopressin) infusion once that immediately aggravated her clinical signs, such as hematuria and thrombocytopenia. Currently, her renal function is normal and her liver function is well preserved (communication with Dr. Mutsuko Konno). Her parents initially stated that they had a non-consanguineous marriage. However, a subsequent ancestral analysis revealed 
that two great-grandparents of USS-B3 on the paternal and maternal sides migrated from the same area (a small fisherman's village) of Iwate to Hokkaido at the end of the 19th century when Hokkaido was an undeveloped island, and the pioneers settled from the Japanese mainland (Honshu). This fisherman's village is located in the northern part of Honshu (Tohoku) faced to Pacific sea, an area severely damaged several times with earthquake and tsunami in the past and most recently in March 11, 2011. In the old days, this small village was isolated from neighbors, and was surrounded by mountains, suggesting that there were many consanguineous marriages within this village.

\section{Family USS-C}

Patient: One male (USS-C3) born in 1972

Brief clinical data: USS-C3 (ADAMTS13 genotype: $\mathbf{c . 4 1 4 + 1 G > A / c . 4 1 4 + 1 G > A}$ ) is the last of 4 children to consanguineous parents (first cousins). Notably, the patient's elder brother (third sibling) died of melena soon after birth. The history of this patient was previously described [39, 40]. At 8 years of age, USS-C3 was clinically diagnosed with USS. Since then, he has received prophylactic FFP (160 mL) infusions every two to four weeks. However, his renal function due to chronic nephritis gradually deteriorated, and in 1995 he required continuous ambulatory peritoneal dialysis (CAPD). Because of repeated peritonitis associated with CAPD, his therapy for renal insufficiency was changed to hemodialysis (three times per week) in 1999. However, his cardiac function decreased, and he eventually died of chronic heart failure in 2010 at 38 years of age.

\section{Family USS-D}

Patient: One female (USS-D4) born in 1978

Brief clinical data: USS-D4 (ADAMTS13 genotype: p.I673F/c.414+1G>A) was born as the second of 2 children to non-consanguineous parents. Her history was previously described $[40,41]$.

\section{Family USS-E}

Patient: One male (USS-E4) born in 1985

Brief clinical data: USS-E4 (ADAMTS13 genotype: p.I673F/p.C908Y) was born as 
the second of 3 children to non-consanguineous parents. His history was previously described [40]. The third sibling had Down's syndrome and died of an unknown cause soon after birth.

\section{Family USS-F}

Patient: One male (USS-F3) born in 1993

Brief clinical data: USS-F3 (ADAMTS13 genotype: p.R193W/c.1244+2T>G) was born as the first of 3 children to non-consanguineous parents. His history was previously described [40]. He currently receives $120 \mathrm{~mL}$ FFP infusions when he develops an occasional hemolytic crisis.

\section{Family USS-G}

Patient: One female (USS-G3) born in 1987

Brief clinical data: USS-G3 (ADAMTS13 genotype: p.R1123C/c.686+1G>A) was born as the third of 4 children to non-consanguineous parents. Her history before she reached 14 years of age was previously described [40]. Of note, her elder sister (second child) had severe jaundice soon after birth and received an exchange blood transfusion. She died of intracranial bleeding after a trivial traffic accident when she was 8 years old. USS-G3 received prophylactic FFP infusions after she was diagnosed with USS, but the infusion intervals gradually increased. Under these circumstances, she became pregnant at 21 and 22 years of age. During the first pregnancy, she had a spontaneous abortion at 5 weeks of gestation. During the second pregnancy, she delivered a premature baby girl (1446 g BW) at 35 weeks of gestation after a cesarean section under extensive prophylactic FFP infusions (normal Japanese female baby at 35 weeks of gestation has a BW of median 2173g). Interestingly, many of placental small vessels were occupied with hyaline thrombosis (communication with Dr. Michiko Kajiwara, details will be published elsewhere by the physicians in charge).

\section{Family USS-H}

Patient: One male (USS-H3) born in 1951

Brief clinical data: USS-H3 (ADAMTS13 genotype: p.A250V/c.330+1 G>A) was born to non-consanguineous parents, but the details were unclear [42]. At 51 years of 
age, he visited a nearby hospital because of a convulsive seizure after hemorrhoidectomy where he was diagnosed with TTP. He had an episode of childhood thrombocytopenia, but there is no additional information. After 51 years of age, he had two episodes of overt TTP, and both were efficiently treated with FFP infusions. In July 2002, he experienced a fourth episode of overt TTP that developed after cholecystectomy, followed by gastrointestinal bleeding that was unsuccessfully treated with FFP infusions and further complicated by renal failure, which ultimately resulted in death at 52 years of age.

\section{Family USS-I}

Patient: One male (USS-I4) born in 1972

Brief clinical data: USS-I4 (ADAMTS13 genotype: p.H234Q/p.R1206X) was born as the second of 2 children to non-consanguineous parents. His elder brother died at 2 years of age with clinical signs that were compatible with TTP, as previously described [43]. At the age of 3 months, USS-I4 developed thrombocytopenia after receiving the diphtheria/pertussis/tetanus vaccine and was diagnosed with idiopathic thrombocytopenic purpura (ITP). Since he was 2 years old, he has experienced repeated overt TTP that has been treated with plasma infusions.

\section{Family USS-J}

Patient: One female (USS-J3) born in 1977 and one male (USS-J4) born in 1979, Brief clinical data: USS-J3 (ADAMTS13 genotype: p.R312C/c.3198delCT) and -J4 (ADAMTS13 genotype: p.R312C/c.3198delCT) are the first and second of 3 children to non-consanguineous parents, respectively. For these 2 patients, severe jaundice was not noted during the newborn period. At 3 years of age, USS-J3 developed a cold followed by purpura with thrombocytopenia and was diagnosed with disseminated intravascular coagulation (DIC). Since then, she has experienced repeated episodes of thrombocytopenia and hemolytic anemia, and was diagnosed with CR-TTP at 6 years of age. USS-J4 had an episode of purpura and thrombocytopenia when he was 5 years old. In 2000, both patients were shown to have a severe deficiency in ADAMTS13 activity in the absence of ADAMTS13 inhibitors. These 2 patients were not given prophylactic FFP infusions. 


\section{Family USS-K}

Patients: Two females (USS-K3 born in 1976 and USS-K4 born in 1978)

Brief clinical data: Patients USS-K3 (ADAMTS13 genotype: p.Y304C/p.T339Rp.Q448E-p.G525D-p.P618A) and -K4 (ADAMTS13 genotype: p.Y304C/p.T339Rp.Q448E-p.G525D-p.P618A) were the first and second to 2 children of non-consanguineous parents, respectively. The history of these two patients was previously reported [12]. In 2003, USS-K3 became pregnant at 27 years old and developed overt TTP at 25 weeks of gestation. She experienced intrauterine fetal death followed by a caesarean delivery with a hysterectomy. On this occasion, she was diagnosed with USS. Since then, she has received prophylactic FFP infusions (80-120 mL) every 4 weeks in an out-patient clinic with a good clinical course. However, at the end of 2010, she had an H1N1 influenza A virus infection that remarkably aggravated thrombocytopenia and was hospitalized for treatment (communication with Dr. Junji Tomiyama).

In 2003, USS-K4, the younger sibling, became pregnant 2 months after her elder sister. She developed mild thrombocytopenia without significant clinical signs at 22 weeks of gestation. She received an ADAMTS13 analysis, which confirmed a diagnosis of USS. While being treated with FFP infusions, she delivered a premature baby by a cesarean section [12]. Since then, she has received FFP infusions of $80 \mathrm{~mL}$ every 3 weeks. In 2008, 5 years after her first pregnancy, USS-K4 became pregnant for the second time and received more frequent FFP infusions (160 mL biweekly). At 29 weeks of gestation, her platelet count suddenly and severely dropped. Thus, at 30 weeks of gestation, a cesarean section was performed, and she delivered a baby (1522g BW) with congenital heart failure due to a ventricular septum defect (details will be published elsewhere by the physicians in charge).

\section{Family USS-L}

Patients: Two females (USS-L2 born in 1967 and USS-L3 born in 1972)

Brief clinical data: Both patients USS-L2 (ADAMTS13 genotype: p.618A-p.Q1302X/p.R125fsX6-p.T339R-p.Q448E) and -L3 (ADAMTS13 genotype: p.618A-p.Q1302X/p.R125fsX6-p.T339R-p.Q448E) were born as the second and fifth of 5 children to non-consanguineous parents. The history of these 2 patients was previously described [12]. At 27 years of age, USS-L2 became pregnant. At 27 
weeks of gestation, she had intrauterine fetal death due to a suspected diagnosis of HELLP (hemolysis, elevated liver-enzymes. low platelets) syndrome. However, she subsequently had 4 children who were all premature and uniformly born at approximately 30 weeks of gestation by a cesarean section with oral aspirin. Patient USS-L3, the younger sister of USS-L2, was diagnosed with ITP at 3 years of age. She had two pregnancies at 25 and 27 years of age. However, she lost both babies at 23 and 24 weeks of gestation, respectively, under a suspected diagnosis of 'habitual abortion'.

\section{Family USS-M}

Patient: Two females (USS-M3 born in 1969 and USS-M4 born in 1971)

Brief clinical data: Patients USS-M3 (ADAMTS13 genotype: p.R193W /p.R349C) and USS-M4 (ADAMTS13 genotype: p.R193W/p.R349C) were born as the second and third of 4 children to non-consanguineous parents. The history of USS-M3 was previously described [12]. USS-M3 was primigravida at 33 years of age, and at 20 weeks of gestation she miscarried with overt TTP. The history of her younger sister, USS-M4, was also previously reported [12]. However, recently Kato et al. [44] reported a more detailed account of the pregnancy of USS-M4, to which we have to make some corrections. According to that report, USS-M4 became primigravida at 28 years of age. Until 28 weeks of gestation, the pregnancy was uneventful when she suddenly stopped feeling fetal movement, resulting in intrauterine fetal death and a subsequent diagnosis of HELLP syndrome. One year later, at the age of 29, she became pregnant for the second time. She was diagnosed with ITP and treated with prednisolone therapy until 37 weeks of gestation, but with incremental low platelet counts $\left(\sim 23 \times 10^{9} / \mathrm{L}\right)$. Soon after this, she underwent a cesarean section after receiving concentrated platelet infusions that transiently increased her platelet counts to $96 \times 10^{9} / \mathrm{L}$. As a result, she delivered a healthy baby. At 32 years of age, she became pregnant for the third time. At 20 weeks of gestation, she developed DIC followed by multi-organ failure, despite extensive treatments, including platelet transfusions. By this time, she had been diagnosed with USS and had received an ADAMTS13 analysis, along with her elder sister, USS-M3. At the age of 36, USS-M4 became pregnant for a fourth time. With extensive FFP infusions, she continued her pregnancy until 36 weeks of gestation and delivered a healthy baby (2506 g BW) by 
natural birth with a skin incision [44].

\section{Family USS-N}

Patient: One female (USS-N6) born in 1986

Brief clinical data: Patient USS-N6 (ADAMTS13 genotype: p.H234R-p.P475S /c.3220delTACC) was born as the last of 4 children to non-consanguineous parents. She had a history of severe neonatal jaundice and childhood thrombocytopenia. Her clinical data were previously reported [11,37]. Of note, she developed a thrombotic occlusion of the left carotid artery at 11 years of age that resulted in right hemiparesis. Subsequently, she developed hypertension and proteinuria, but these clinical signs have significantly improved during a long clinical course with prophylactic FFP infusions, although some neurological sequelae have persisted (communication with Dr. Seiji Kinoshita).

\section{Family USS-O}

Patient: One female (USS-O4) born in 1958

Brief clinical data: Patient USS-O4 (ADAMTS13 genotype: p.I178T /p.Q929X) was the second of 2 children to non-consanguineous parents. The history of USS-O4 was previously described [12]. At the age of 26, USS-O4 became pregnant. At 23 weeks of gestation, she developed thrombocytopenia and delivered a premature infant at 25 weeks of gestation who died soon after birth. After delivery, she developed overt TTP that was rescued with plasma exchange. At 31 years of age, she became pregnant for the second time while receiving prophylactic FFP infusions every one to two weeks. At 8 weeks of gestation, she developed proteinuria and thrombocytopenia, and therefore received more frequent FFP infusions. At 36 weeks of gestation, she delivered a healthy baby girl.

\section{Family USS-P}

Patient: One male (USS-P3) born in 1971

Brief clinical data: The clinical data for patient USS-P3 (ADAMTS13 genotype: p.C908Y/p.C322G-p.T323R-p.F324L, de novo mutation) were previously described [45]. Briefly, USS-P3 was the second of 4 children to non-consanguineous parents. The first and fourth siblings died of an abortion at 6 and 22 weeks of 
gestation, respectively, due to unknown causes. At 3 years of age, USS-P3 had clinical signs of overt TTP, which was efficiently treated with FFP infusions. He was repeatedly treated with FFP infusions when overt TTP developed. Thus, after 21 years of age, the prophylactic FFP infusions were continued.

\section{Family USS-Q}

Patient: Two males, (USS-Q1) born in 1983 and (USS-Q2) born in 1988

Brief clinical data: Patients USS-Q1 (ADAMTS13 genotype: p.G227R-p.G1181R /p.C908Y) and -Q2 (ADAMTS13 genotype: p.G227R-p.G1181R/p.C908Y) were the first and third of 3 children to non-consanguineous parents. Their detailed clinical data during childhood were reported in 1990 [46].

\section{Family USS-R}

Patient: One female (USS-R5) born in 1982

Brief clinical data: USS-R5 (ADAMTS13 genotype: p.R193W/ p.T339R-p.Q448E-p.A606P-p.P618A) was the last of 3 children to non-consanguineous parents. The history of USS-R5 was previously reported [12]. Briefly, at 23 years of age, she became pregnant. At 23 weeks of gestation, she developed mild thrombocytopenia, and at 31 weeks of gestation, she had sudden intrauterine fetal death. After a cesarean section, she developed overt TTP, which was treated with plasma exchange and steroids. On this occasion, she was diagnosed with USS after her ADAMTS13 activity and ADAMTS13 inhibitor status were analyzed. This patient did not receive prophylactic FFP infusions.

\section{Family USS-S}

Patient: One male (USS-S3) born in 1982

Brief clinical data: USS-S3 (ADAMTS13 genotype: undetermined) was born to non-consanguineous parents. Neither his childhood nor family history has been obtained. The patient was clinically diagnosed with USS at a nearby hospital when he was 4 years old. Since then, he has received prophylactic FFP infusions every two weeks at the same hospital. In 2002, USS-S3 was confirmed to have a severe deficiency in ADAMTS13 activity in the absence of ADAMTS13 inhibitors. Furthermore, the ADAMTS13 activities for his father and mother were 34.2\% and 
47.6\%, respectively. This family has not been examined for ADAMTS13 gene mutations.

\section{Family USS-T}

Patient: One female (USS-T4) born in 1981

Brief clinical data: USS-T4 (ADAMTS13 genotype: c.3220delTACC /c.3220delTACC) was born as the second of 2children to non-consanguineous parents. Soon after birth, she developed severe neonatal jaundice and received exchange blood transfusion for 3 times [47]. One month after birth, she developed hematuria with thrombocytopenia, which led to a clinical diagnosis of USS. She received DDAVP infusion once at the age of 4 , by which her platelet count promptly dropped and her clinical signs were aggravated, in accord with a transient disappearance of larger VWFMs from plasma [47]. Thus, she has received prophylactic FFP infusions every 2 weeks since 1992. In 1998, USS-T4 was confirmed to have a severe deficiency in ADAMTS13 activity in the absence of ADAMTS13 inhibitors. She had a homozygous ADAMTS13 gene mutation of c.3220del TACC/c.3220delTACC (exon 24).

\section{Family USS-U}

Patient: One female (USS-U3) born in 1990

Brief clinical data and remarks: USS-U3 (ADAMTS13 genotype: c.2259delA /c.2259delA) was born as the second of 2 children to consanguineous parents (second cousins). Soon after birth, she developed severe neonatal jaundice that required an exchange transfusion. She was clinically diagnosed with USS at 4 months of age. In 1998, USS-U3 was confirmed to have a severe deficiency in ADAMTS13 activity but no ADAMTS13 inhibitors. She was homozygous for an ADAMTS13 gene mutation of c.2259delA/c.2259delA (exon 19). This patient has continued prophylactic FFP infusions.

\section{Family USS-V}

Patient: One female (USS-V3) born in 1983

Brief clinical data: USS-V3 (ADAMTS13 genotype: p.W1081X/p.R193W) was born as the second of 2 children to non-consanguineous parents. Soon after birth, she 
developed severe neonatal jaundice that required an exchange blood transfusion. She was clinically diagnosed with USS at 4 years of age. In 1998, USS-V3 was confirmed to have a severe deficiency in ADAMTS13 activity but no ADAMTS13 inhibitors. She had a compound heterozygous ADAMTS13 gene mutation with p.W1081X (exon 24) from her father and p.R193W (exon 6) from her mother. The patient has been administered FFP infusions on demand.

\section{Family USS-W}

Patient: One female (USS-W4) born in 1990

Brief clinical data and remarks: USS-W4 (ADAMTS13 genotype: p.Q448E-p.G550R/p.P475S) was born as the second of 2 children to non-consanguineous parents. She did not have episodes of severe jaundice as a newborn. At 2 years of age, she developed pneumonia followed by thrombocytopenia. Since then, she has had repeated episodes of thrombocytopenia and hemolytic anemia that have coincided with various infections, resulting in a diagnosis of Evans syndrome. In 2005, USS-W4 was confirmed to have a severe deficiency in ADAMTS13 activity in the absence of ADAMTS13 inhibitors. An ADAMTS13 gene analysis in USS-W4 suggested that she was a compound heterozygote with a p.G550R (exon 14) mutation from her father and an unidentified DCM from her mother. This patient has received prophylactic FFP infusions every two weeks.

\section{Family USS-X}

Patient: One female (USS-X5) born in 1963

Brief clinical data: USS-X5 (ADAMTS13 genotype: p.G1181R/p.P475S) was the last of 4 children to non-consanguineous parents. She did not have severe neonatal jaundice or childhood thrombocytopenia. She had two pregnancies at the ages of 24 and 26 years that yielded two children. During her first pregnancy, she had pregnancy-induced hypertension, but the details are unknown. At 32 years of age, she developed nephrotic syndrome, followed by repeated hemolytic anemia and thrombocytopenia of an unknown cause. None of the laboratory markers were indicative of connective tissue disease. She underwent a splenectomy at the age of 36. In 2004, she had a relapse of nephrotic syndrome with hemolytic anemia and 
thrombocytopenia that was treated with high-dose steroid therapy with limited success. At this time, her plasma ADAMTS13 activity levels and ADAMTS13 inhibitor status were examined, and she was determined to have a severe deficiency in ADAMTS13 activity in the absence of ADAMTS13 inhibitors. The same results were obtained 6 months later with a different plasma specimen. An ADAMTS13 gene analysis in USS-X5 identified no DCMs, but revealed two SNPs of p.P475S from her mother and p.G1181R from her father. In 2007, she developed systemic lupus erythematosus (SLE) and was moved to a different hospital, after which we were unable to follow her clinical and laboratory data. From these results, USS-X5 could be considered to be a possible USS.

\section{Family USS-Y}

Patient: One female (USS-Y3) born in 1960

Brief clinical data: USS-Y3 (ADAMTS13 genotype: p.G385E/ p.R1206X) was the last of 3 children to non-consanguineous parents. It is unclear whether this patient had a history of severe neonatal jaundice. However, during childhood she had an episode of thrombocytopenia and was diagnosed with ITP. She has a history of fresh whole blood transfusions, although the details are unclear. Since then, she had no remarkable changes. However, at 45 years of age, she suddenly developed thrombocytopenia and hemolytic anemia, leading to a diagnosis of Evans syndrome. On this occasion, her physician noted many schistocytes on her blood film, and USS-Y3 was confirmed to have a severe deficiency in ADAMTS13 activity in the absence of ADAMTS13 inhibitors. An ADAMTS13 gene analysis determined that she was a compound heterozygote with p.G385E (exon 10) from her father and p.R1206X (exon 26) from her mother.

\section{Family USS-Z}

Patient: One female (USS-Z3) born in 1971

Brief clinical data: USS-Z3 (ADAMTS13 genotype: p.R193W /p.R193W) was the last of 3 children to consanguineous parents (second cousins). Her clinical data were previously described [12]. Briefly, she became pregnant for the first time at 25 years of age, and at 12 weeks of gestation, she developed thrombocytopenia and was diagnosed with pregnancy-associated ITP. At 32 weeks of gestation, she had a live 
birth by cesarean section, and then developed overt TTP, which was treated with daily plasma exchange. This patient was referred to our laboratory in 1998, and USS-Z3 was confirmed to have a severe deficiency in ADAMTS13 activity in the absence of ADAMTS13 inhibitors. This patient did not receive prophylactic FFP infusions, and she had more than five TTP episodes between 1998-2005. Each episode was treated with $320 \mathrm{~mL}$ plasma infusions. She has been receiving prophylactic FFP infusions every two weeks.

\section{Family USS-AA}

Patient: One female (USS-AA3) born in 1987

Brief clinical data: USS-AA3 (ADAMTS13 genotype: not performed) was the first of 2 chidren born to non-consanguineous parents. She had neither an apparent history of severe neonatal jaundice nor thrombocytopenia during childhood. At 19 years of age, she suddenly developed petechiae, and her laboratory data indicated severe thrombocytopenia and hemolytic anemia. Thus, her ADAMTS13 activity was examined and revealed a severe deficiency in ADAMTS13 activity but no ADAMTS13 inhibitors. Plasma exchange therapy was performed, and her platelet counts normalized. One month later, her ADAMTS13 activity and ADAMTS13 inhibitor status were re-tested and yielded the same results. In addition, her family members had the following ADAMTS13 activities: father (32\%), mother (53\%), and younger sister (46\%). An ADAMTS13 gene analysis was not performed in this family because permission was not obtained. In 2009, we determined that USS-AA3 had a normal platelet count $\left(201 \times 10^{9} / \mathrm{L}\right)$, but her ADAMTS13 activity was still very low $(<0.5 \%$ of normal) with no ADAMTS13 inhibitors. Since this point, we have been unable to obtain more up-dated information on this patient.

\section{Family USS-BB}

Patient: One male (USS-BB3) born in 1947

Brief clinical data: USS-BB3 (ADAMTS13 genotype: p.R193W/p.R193W) was the first of 3 children to consanguineous parents (first cousins). His younger sister died of 'purpura of unknown cause' at 23 years of age. It is unclear whether USS-BB3 experienced episodes of severe jaundice as a newborn or childhood thrombocytopenia. He was married and had 3 children. At 55 years of age, he 
developed overt TTP, which was successfully treated with plasma exchange. When he was 59 years old, he developed hematuria and was admitted to a nearby hospital, where an ADAMTS13 analysis showed that he had a severe deficiency in ADAMTS13 activity but no ADAMTS13 inhibitors. An ADAMTS13 gene analysis indicated that he was a homozygote with p.R193W (exon 6) (communication with Dr. Toshi Imai, details will be reported by the physicians in charge).

\section{Family USS-CC}

Patient: One male (USS-CC5) born in 2004

Brief clinical data: USS-CC5 (ADAMTS13 genotype: p.Q723K/p.R398C) was the last of 3 children to non-consanguineous parents. Soon after birth, he developed Coombs-negative hemolytic anemia and was treated with an exchange blood transfusion. At 7 months of age, he became infected with influenza A virus that aggravated his thrombocytopenia and hemolytic anemia. At 32 months of age, he suddenly developed a transient disturbance in his ability to walk and converse. On this occasion, an ADAMTS13 analysis revealed that USS-CC5 had a severe deficiency in ADAMTS13 activity but no ADAMTS13 inhibitors. An ADAMTS13 gene analysis indicated that he was a compound heterozygote with p.Q723K (exon 18) from his father and p.R398C (exon 10) from his mother. Since he was diagnosed with USS, he has received prophylactic FFP infusions every two weeks.

\section{Family USS-DD}

Patient: One female (USS-DD5) born in 2007

Brief clinical data: USS-DD5 (ADAMTS13 genotype: p.R268P/p.Y304C) was born as the last of 3 children to non-consanguineous parents. One day after birth, the patient developed hematuria, petechiae, moderate jaundice, and thrombocytopenia, suggesting immune thrombocytopenia. A platelet transfusion was performed that subsequently aggravated her jaundice, which was ameliorated with albumin infusions and phototherapy from three directions. Therefore, an exchange blood transfusion was not performed. Her platelet counts were maintained around $60-100 \times 10^{9} / \mathrm{L}$, and at 15 days of age the physician infused FFP at a dose of $10 \mathrm{~mL} / \mathrm{kg}$ due to suspected USS. This treatment markedly increased her platelet counts (written information from Dr. Hitoshi Miyabayashi). One month after birth, an ADAMTS13 analysis 
showed that the patient had a severe deficiency in ADAMTS13 activity but no ADAMTS13 inhibitors. An ADAMTS13 gene analysis determined that USS-DD5 was a compound heterozygote with p.R268P (exon 7) from her father and p.Y304Y (exon 8) from her mother. The patient did not receive prophylactic FFP infusions.

\section{Family USS-EE}

Patient: One male (USS-EE4) born in 2003

Brief clinical data and remarks: USS-EE4 (ADAMTS13 genotype: c.2259delA/c.2259delA) was born as the second child of bi-ovular twins by a caesarean delivery at 37 weeks of gestation to consanguineous parents (second cousins). Soon after birth, USS-EE4 received an exchange blood transfusion under a diagnosis of DIC. However, the other twin did not have these complications. Since then, USS-EE4 has continued to experience mild thrombocytopenia. At 18 months of age, his platelet count dropped to $11 \times 10^{9} / \mathrm{L}$, and schistocytes appeared on a blood film when the patient had a rotavirus infection. The patient subsequently experienced repeated episodes of thrombocytopenia and hemolytic anemia associated with a variety of infectious diseases. At the age of 4 years and 7 months, the patient was admitted to a nearby hospital because of exacerbated asthmatoid bronchitis together with severe thrombocytopenia $\left(4 \times 10^{9} / \mathrm{L}\right)$. After being diagnosed with ITP, the patient was administered high-dose immunoglobulin therapy with steroid therapy, but there was no clinical improvement (written information from Dr. Masahiro Migita). An ADAMTS13 analysis showed a severe deficiency in ADAMTS13 activity but no ADAMTS13 inhibitors. An ADAMTS13 gene analysis in USS-EE4 identified a homozygous mutation of c.2259delA (exon 19). This patient did not receive prophylactic FFP infusions.

\section{Family USS-FF}

Patient: One female (USS-FF3) born in 1991

Brief clinical data: USS-FF3 (ADAMTS13 genotype: p.Q449X/p.Q449X) was born as the first of 2 children to non-consanguineous parents [48]. As a newborn, the patient had moderate jaundice that required phototherapy, but no exchange blood transfusion was required. She also had a history of chronic thrombocytopenia as a newborn, but did not receive specific treatment. At 6 years of age, she developed 
severe thrombocytopenia and hemolytic anemia, and an ADAMTS13 analysis revealed a severe deficiency in ADAMTS13 activity but no ADAMTS13 inhibitors. An ADAMTS13 gene analysis was performed at the laboratory of Dr. David Ginsburg, where a homozygous mutation of p.Q449X (exon 6) was identified ([40] and written communication with Dr. Yoji Sasahara). Since the USS diagnosis was confirmed, the patient has received FFP infusions $(5 \mathrm{~mL} / \mathrm{kg}$ ) every two weeks.

\section{Family USS-GG}

Patient: One male (USS-GG2) born in 1931

Brief clinical data: USS-GG2 (ADAMTS13 genotype: p.C1024R/p.C1024R) was born as the fifth of 7 children to consanguineous parents (first cousins). The ancestors of this family can be traced back to Kochi on Shikoku Island. The first two siblings died of an unknown etiology during childhood. Interestingly, USS-GG2 suddenly developed overt TTP with neurological signs at 63 years of age and was admitted to a nearby hospital. Before this, he had never had an episode of anemia or thrombocytopenia. He was treated with plasma infusions because plasma exchange was not readily available at that hospital. The next day, his neurological signs dramatically improved. He subsequently has experienced repeated episodes of overt TTP, resulting in a clinical diagnosis of CR-TTP, which was treated with biweekly prophylactic FFP infusions (320-480 mL per each). However, at 77 years of age, he had cerebellar bleeding. Thus, he received an ADAMTS13 analysis that showed a significant reduction in ADAMTS13 activity (2.4-3.4\% of normal on 3 different occasions) but no ADAMTS13 inhibitors. An ADAMTS13 gene analysis revealed that he was a p.C1024R/p.C1024R (exon 24) homozygote, confirming the USS diagnosis. Under prophylactic FFP infusions, he was alive until 79 years old, but he suddenly died of stroke in 2011 at the age of 79 (communication with Dr. Fumihiro Taguchi, details will be published elsewhere by the physician in charge).

\section{Family USS-HH}

Patient: One female (USS-HH4) born in 2003

Brief clinical data: USS-HH4 (ADAMTS13 genotype: p.Q449X/ c.4119delG) was born as the second of 2 children to non-consanguineous parents. Soon after birth, she developed Coombs-negative hemolytic anemia that was treated with an exchange 
blood transfusion. In 2005, she had three episodes of thrombocytopenia and hemolytic anemia that occurred concomitantly with fever or the chicken pox. Therefore, her ADAMTS13 activity was assayed, and she was determined to have a severe deficiency in ADAMTS13 activity but no ADAMTS13 inhibitors. An ADAMTS13 gene analysis revealed that she was a compound heterozygote with p.Q449X (exon 12) from her father and c.4119delG (exon 29) from her mother. Although she had a history of severe neonatal jaundice followed by an exchange blood transfusion, she subsequently has only had mild clinical signs and has not received prophylactic FFP infusions. She receives FFP infusions only when her platelet count severely drops.

\section{Family USS-II}

Patient: One female (USS-II3) born in 1977

Brief clinical data: USS-II3 (ADAMTS13 genotype: not performed) was born by a cesarean section as the fourth and final pregnancy of her mother at 40 weeks of gestation. Her parents were non-consanguineous. Her mother had previously had two abortions ( 5 and 3 months of gestation) and a stillbirth (9 months of gestation) before USS-II3 was born. On the second day after birth, USS-II3 was treated with an exchange blood transfusion because of severe jaundice and thrombocytopenia. One month later, the patient was discharged but the thrombocytopenia continued, suggesting ITP. Since then, she has received whole blood transfusions when her platelet counts have dropped to $10 \times 10^{3} / \mathrm{L}$. At 9 months of age, the patient was clinically diagnosed with TTP. She was administered FFP infusion when severe thrombocytopenia developed. At 10 years of age, she underwent a splenectomy but there was no clinical improvement. The prophylactic FFP infusions have continued. At 21 years of age, she was diagnosed with USS after it was determined that she had a severe deficiency in ADAMTS13 activity but no ADAMTS13 inhibitors. She currently receives prophylactic FFP infusions (120 mL) every week.

\section{Family USS-JJ}

Patient: One male (USS-JJ3) born in 1980

Brief clinical data: USS-JJ3 (ADAMTS13 genotype: c.1885delT/p.C908Y) was born as the last of 4 children to non-consanguineous parents. He had no history of 
exchange blood transfusions as a newborn. At 2 years of age, he suddenly complained of abdominal pain and developed hemolytic anemia, hematuria, and thrombocytopenia. On this occasion, he was diagnosed with acute renal insufficiency due to diarrhea-negative atypical HUS at a nearby hospital. Under this diagnosis, he received conservative therapy, including heparin, anti-platelet drugs, and red blood cell transfusion, but no platelet or FFP infusions. During the next 14 years, he occasionally experienced overt HUS. At 12 years of age, his physician noticed that the FFP infusions were highly effective and improved his clinical manifestations, suggesting a clinical diagnosis of CR-TTP. Since 1996, he has received FFP infusions (160-240 $\mathrm{mL}$ per each) when his platelet counts have dropped below $100 \times 10^{9} / \mathrm{L}$, and has been administered FFP infusions with a greater volume (320-480 mL) during instances of overt TTP. In 1998, he was diagnosed with USS after an ADAMTS13 analysis revealed a severe deficiency in ADAMTS13 activity but no ADAMTS13 inhibitors. Furthermore, he was a heavy drinker, which increased the frequency of overt TTP. Under these unhealthy conditions, the prophylactic FFP infusions were sometimes interrupted. Thus, when he was 25 years old, he experienced a cerebral infarction and the prophylactic FFP infusions were re-started. Nevertheless, one year later, he had severe renal insufficiency that required hemodialysis. Thus, he currently receives maintenance dialysis therapy and prophylactic FFP infusions of $240 \mathrm{~mL}$ per week. In 2009, an ADAMTS13 activity analysis revealed a severe deficiency in ADAMTS13 activity but no ADAMTS13 inhibitors. An ADAMTS13 gene analysis revealed that he was a compound heterozygote with c.1885delT (exon 16) and p.C908Y (exon 21), but that was not performed to his parents.

\section{Family USS-KK}

Patient: One female (KK3) born in 1976

Brief clinical data: USS-KK3 (ADAMTS13 genotype: not performed) was born as the second of 3 children to non-consanguineous parents. She had no history of exchange blood transfusion during the newborn period. At the age of 2, she developed thrombocytopenia and was diagnosed of ITP. She received a steroid therapy for thrombocytopenia at the age of 17 but without improvement, and then received splenectomy. When she was a university student at the age of 20, she 
developed thrombocytopenia and hemolytic anemia after heavily drinking alcohol, and on this occasion she was clinically diagnosed of TTP at Shinshu university hospital in Nagano. A diagnosis of CR-TTP was made by Dr. Miha Furlan at University of Bern in 1998, after analyzing ADAMTS13, which showed a severe deficiency of the activity but without its inhibitors (these results were re-confirmed in March 2011 using chromogenic act-ELISA). Her mother and two siblings had a slightly decreased ADAMTS13 activity (25 50\%) (communication with Drs. Fumihiro Ishida and Hikaru Kobayashi). Now, the patient receives the prophylactic FFP infusions ( $240 \mathrm{ml}$ per each) every 3 weeks. The ADAMTS13 gene analysis has not been performed.

\section{Family USS-LL}

Patient: One female (LL4) born in 1981.

Brief clinical data: USS-LL4 (ADAMTS13 genotype: p.C438S/p.T339R-p.Q448E-p.P618A-p.G909R) was born as the last of 2 children to non-consanguineous parents. She had no history of exchange blood transfusion during the newborn period. At the age of 14, she was diagnosed of HUS of unknown etiology, and received hemodialysis. During 1996-2001, she repeated overt TTP when she had various infectious diseases, and in each occasion she was treated with FFP infusions. In 2002, she was diagnosed of USS after analyzing ADAMTS13, showing a severe deficiency of the activity but without its inhibitors in our laboratory. Since then, however, a low-titer ADAMTS13 inhibitor (less than $1.4 \mathrm{BU} / \mathrm{mL}$ ) was detected in a few occasions, but its clinical significance was not well evaluated. Her parents and elder sister are asymptomatic and have a slightly decreased ADAMTS13 activity (27 57\%). The ADAMTS13 gene analysis in this patient revealed a compound heterozygote of p.C438S (exon 12) from her father and p.G909R (exon 21) from her mother. She had been treated with FFP infusions on demand. Most recently, she has become pregnant, and her inhibitor titers are kept below $0.5 \mathrm{BU} / \mathrm{ml}$. Thus, the prophylactic FFP infusions (10 ml/kg BW) have been started biweekly, and so far no increase of ADAMTS13 inhibitor titer has been observed (communication with Dr. Yoshiyuki Ogawa).

\section{Characterization and allelic numbers of ADAMTS13 gene mutations in Japanese}




\section{patients with USS}

Of our 43 USS-patients, 39 received an ADAMTS13 gene analysis while it was not performed in 4 patients (USS-S3, AA3, II3 and KK3). Nine of these 39 USS-patients were homozygous for ADAMTS13 gene mutations, and 29 were the compound heterozygotes, including one patient (USS-W4) with p.G550R mutation on one allele while DCM on the other allele was unidentified. In the remaining one patient (USS-X5), two SNPs (p.P475S/p.G1181R) but not DCMs were identified on each allele. Of these 39 USS-patients, five were siblings that each belonged to different families. Thus, the 65 [2 × (39-5)-3] allelic numbers of DCMs in these patients are summarized in Table 3. Interestingly, these mutations are quite different from those reported in the US and Western countries [3, 49-66], except for p.R268P. However, the p.R349C mutation was previously reported in a Chinese USS patient in Hong Kong [67], and c.330+1G >A was identified in a Korean patient [68]. Thus, it is likely that specific ADAMTS13 gene mutations are more common among certain ethnicities. In this regard, the mutation of p.R268P is quite unique, because of the same mutation was reported by Veyradier et al. [55] in France, but in a Haitian patient.

The ADAMTS13 gene mutation with the highest frequency in Japan was p.R193W ( $\mathrm{n}=8$ ), followed by the remaining alleles in order of descending frequency: p.Q449X ( $\mathrm{n}=5)$, p.C908Y ( $\mathrm{n}=4)$, c.2259delA ( $\mathrm{n}=4)$, etc. The p.Q449X mutation was localized to the northern part (Tohoku) of Honshu, c.2259delA to Kyushu, p.C908Y to western Japan, and p.R193W to a relatively wide area across Japan but more frequently in western Japan, suggesting some geographical specificity in these mutations. (Fig. 1)

\section{Plasma levels of ADAMTS13 activity, ADAMTS13 inhibitor, and IgG-type anti-ADAMTS13 binding antibody in USS-patients}

Most of our USS-patients had the plasma levels of ADAMTS13 activity with a less than $0.5 \%$ of the normal (Table 1), but USS-GG2 alone had the ADAMTS13 activity of $2.4-3.4 \%$ of the normal, measured in 3 different occasions, as described above. Further, seven USS-patients (USS-F3, J3, K3, H3, Q1, S3, and LL4) had a trace amount of ADAMTS13 activity (0.6-1.8\% of the normal) in some occasions, of whom 4 patients (USS-J3, K3, Q1, and LL4) had the ADAMTS13 activity below 
$0.5 \%$ of the normal in different occasions The reason for this slight variation of plasma ADAMTS13 activity in our patients is presently unknown.

As for the ADAMTS13 inhibitors, all of our USS-patients had the plasma level of less than $0.5 \mathrm{BU} / \mathrm{ml}$, but with one exception (USS-LL4), who showed the inhibitor titers ranging from less than 0.5 to $1.4 \mathrm{BU} / \mathrm{ml}$.

In regard to the IgG-type anti-ADAMTS13 binding antibody, 36 of 43 USS-patients did not have it (shown as the titer of $25 \mathrm{X}$ or less than $25 \mathrm{X}$ in Table 1). However, 7 patients (USS-K3, K4, X5, AA3, EE4, II3, and LL4) had the antibody titers ranged from $50 \mathrm{X}$ to $400 \mathrm{X}$ in some occasions. Clinical significance of the IgG-type anti-ADAMTS13 binding antibody is also unclear at moment, but notably 6 of these 7 patients are female.

\section{Discussion}

Since ADAMTS13 was originally discovered, one major question has been why USS-patients who consistently lack ADAMTS13 activity do not always experience acute symptoms of overt TTP. Furthermore, symptoms often become evident only when the patients have infections or become pregnant $[12,69]$. In both instances, vascular endothelial cell injury may be involved, and these cases have been indirectly associated with elevated plasma levels of cytokines or soluble thrombomodulin [70]. Consistent with these observations, studies on two different groups of ADAMTS13 gene knock-out mice revealed that UL-VWFMs were detectable in the blood, although the mice did not exhibit acute symptoms [71, 72]. Considering these results, investigators have assumed that a deficiency in ADAMTS13 activity is prothrombotic, but alone is insufficient to provoke acute symptoms. Thus, second hits or triggers must exist. Related to this hypothesis, it has been said that there are two clinical features of USS, termed the "early-onset" and "late-onset" phenotypes. To partially address this question, we have extensively analyzed the natural histories and ADAMTS13 genotypes of 43 Japanese patients with USS.

This study has two advantages. One advantage is that Japan has four basic small islands, Hokkaido, Honshu, Shikoku, and Kyushu, that are favorable for tracing the ancestral roots of a targeted USS family. This is because USS patients tend to live 
near their parents or healthy relatives in order to receive medical support when they develop overt signs of TTP. In fact, before ADAMTS13 was discovered in 2001, nine patients were clinically diagnosed with USS or congenital CR-TTP in Japan, and none of these patients have moved to other areas or countries. The other advantage of this study can be attributed to the development of two convenient ADAMTS13 activity assays in our country, FRETS-VWF73 [29] and the chromogenic ADAMTS13-ac-ELISA [28]. Both assays are now used worldwide, and in 1998 Nara Medical University started voluntarily using the VWFM assay to meet the requests of clients across Japan. In 2005, the act-ELISA shortened the time required to diagnose TTP, and more importantly facilitated the identification of new USS-patients in Japan.

Although severe neonatal jaundice that requires exchange blood transfusion has been a hallmark of USS, this clinical sign was present in 18 of 43 (42\%) patients in this study. Because of this clinical sign, 4 (/18) physicians correctly diagnosed their patient with USS before the patient reached 6 months of age, and 10 (/18) physicians required 6 years to reach a USS diagnosis. On the other hand, among 25 USS patients without severe newborn jaundice, two (/25) were correctly diagnosed within 6 months of age, and six (/25) were diagnosed within 6 years. As a whole, 25 of 43 (58\%) USS patients were correctly diagnosed before they reached 15 years of age, including 12 females and 13 males, indicating that there is no gender disparity in diagnosing USS during childhood. These 25 patients would be unanimously considered to have the "early-onset phenotype". However, the remaining 18 USSpatients were diagnosed after 15 years of age. This raises the question of whether these patients were the true "late-onset phenotype" or not. One particularly interesting result was that 15 (/18) patients were diagnosed between 15 and 45 years of age, and interestingly they were all female. Furthermore, among these 15 female patients, nine were diagnosed in association with pregnancy. On the other hand, the remaining 3 patients (USS-H3, -BB3, and -GG2) were diagnosed after 45 years of age, and they were all male, which sharply contrasts the previous scenario. Thus, the natural history of these 3 male patients appeared to be an excellent means to analyze the pathogenesis of the "late-onset phenotype". Among these patients, USS-H3 with a p.A250V/c.330+1G > A genotype had an episode of thrombocytopenia, but there are few clinical details and the patient died of renal failure in 2002 [42], Thus, no further 
results on USS-H3 are available.

However, two other males, USS-BB3 and USS-GG2, had received annual health examinations during adulthood, and there were no apparent abnormalities until sudden and overt TTP developed at 55 and 63 years of age, respectively. This may indicate that the clinical signs of TTP were very mild during their childhood and adulthood, and any symptoms might have been attributed to isolated mild thrombocytopenia. Interestingly, these two elderly men carried two different homozygous ADAMTS13 gene mutations, p.R193W/p.R193W and p.C1024R/p.C1024R, respectively. We previously reported that the p.R193W protein was present in the plasma of patient USS-Z3 [12, 73]. In this study we also determined that the p.C1024R protein was present in the plasma of patient USS-GG2 (data not shown). Furthermore, in vitro expression studies using HeLa cells that were transfected with either of these two mutant gene plasmids showed that each protein was consistently secreted into the culture medium but had much reduced activity compared to the wild-type protein ([39] and unpublished data). Consistent with these observations, the ADAMTS13 activity of patient USS-GG2 was mildly reduced (2.4-3.4\% of the normal) on 3 different occasions. As for the homozygous p.R193W/p.R193W mutation, we identified another female patient (USS-Z3) who was correctly diagnosed with USS at 27 years of age as a result of pregnancy-associated TTP at 25 years of age. Her past history was well recorded, and indicated that she had mild jaundice as a newborn and thus did not receive an exchange blood transfusion. However, she was diagnosed with ITP with isolated thrombocytopenia at 7 years of age. Taken together, these results indicate that the phenotype of the homozygous p.R193W/p.R193W mutation is mild. Therefore, patients carrying this mutation would presumably have mild thrombocytopenia during childhood, as shown in USS-Z3, unless they are exposed to strong stimuli such as a cytokine storm during influenza virus infection. However, after adolescence the gender disparity apparently determines the fate of these USS-patients. Pregnancy undoubtedly is a strong inducer of overt TTP in female USS-patients, although the pathogenesis is not fully elucidated. However, it is now well established that plasma VWF levels remarkably increase as gestation progresses, along with the appearance of UL-VWFMs, which are accompanied by reduced ADAMTS13 activity due to consumption, even in normal pregnant women $[74,75]$. 
Thus, in pregnant USS women, an enormous excess of the substrate (larger VWFM) relative to the ADAMTS13 enzyme is the most plausible pathogenic mechanism.

As a consequence, our studies here have re-confirmed that pregnancy, influenza infection, and DDAVP administration can be the strong triggers inducing overt TTP in USS-patients. Besides, now it is indicated that the aging, interferon therapy, and heavily drinking alcohol could be the additional modifiers aggravating clinical signs of USS-patients.

Given that the p.R193W mutation is a frequent DCM for USS in Japan, male patients carrying this mutation might not exhibit clinical signs of thrombosis at a younger age. However, as they age, multi-factorial endogenous and exogenous causes mentioned above would facilitate thrombotic events, leading to brain infarctions and chronic renal failure as a result of microcirculation disturbances. We speculate that thrombotic events in the brain or kidney, which still have an unknown pathogenesis, might result from ADAMTS13 gene abnormalities. Our examination of the natural history in this large cohort of USS-patients with ADAMTS13 mutations may shed light on these important diseases. Thus, here we emphasize again an importance of the assay for ADAMTS13 activity as a routine test to make and/or exclude a diagnosis of USS, when physicians meet the patients with thrombocytopenia of unknown etiology, not only in childhood but also in adulthood.

\section{Acknowledgements}

This work was supported in part by research grants from the Ministry of Health, Labor, and Welfare of Japan, and the Ministry of Education, Culture, Sports, Science and Technology of Japan. YF dedicates this paper to the late Professors Theodore S. Zimmerman and Hiromu Fukui, who both encouraged me to be involved in the research on VWF and its clinical application.

\section{Disclosure of Conflict of Interests}

YF is a clinical advisory board for Baxter Bioscience. 


\section{References}

1 Fujimura Y, Matsumoto M, Yagi H, Yoshioka A, Matsui T, Titani K. Von Willebrand factor-cleaving protease and Upshaw-Schulman syndrome. Int J Hematol. 2002; 75: 25-34.

2 Zheng X, Chung D, Takayama TK, Majerus EM, Sadler JE, Fujikawa K. Structure of von Willebrand factor-cleaving protease (ADAMTS13), a metalloprotease involved in thrombotic thrombocytopenic purpura. J Biol Chem. 2001; 276: 41059-63.

3 Levy GG, Nichols WC, Lian EC, Foroud T, McClintick JN, McGee BM, Yang AY, Siemieniak DR, Stark KR, Gruppo R, Sarode R, Shurin SB, Chandrasekaran V, Stabler SP, Sabio H, Bouhassira EE, Upshaw JD, Jr., Ginsburg D, Tsai HM. Mutations in a member of the ADAMTS gene family cause thrombotic thrombocytopenic purpura. Nature. 2001; 413: 488-94.

4 Soejima K, Mimura N, Hirashima M, Maeda H, Hamamoto T, Nakagaki T, Nozaki C. A novel human metalloprotease synthesized in the liver and secreted into the blood: possibly, the von Willebrand factor-cleaving protease? J Biochem. 2001; 130: $475-80$.

5 Sadler JE. Von Willebrand factor, ADAMTS13, and thrombotic thrombocytopenic purpura. Blood. 2008; 112: 11-8.

6 Waters AM, Licht C. aHUS caused by complement dysregulation: new therapies on the horizon. Pediatr Nephrol. 2011; 26: 41-57.

7 George JN. Clinical practice. Thrombotic thrombocytopenic purpura. $N$ Engl J Med. 2006; 354: 1927-35.

8 Veyradier A, Obert B, Haddad E, Cloarec S, Nivet H, Foulard M, Lesure F, Delattre P, Lakhdari M, Meyer D, Girma JP, Loirat C. Severe deficiency of the specific von Willebrand factor-cleaving protease (ADAMTS 13) activity in a subgroup of children with atypical hemolytic uremic syndrome. J Pediatr. 2003; 142: 310-7.

9 Remuzzi G, Galbusera M, Noris M, Canciani MT, Daina E, Bresin E, Contaretti S, Caprioli J, Gamba S, Ruggenenti P, Perico N, Mannucci PM. von Willebrand factor cleaving protease (ADAMTS13) is deficient in recurrent and familial thrombotic thrombocytopenic purpura and hemolytic uremic syndrome. 
Blood. 2002; 100: 778-85.

$10 \quad$ Moake JL. Thrombotic microangiopathies. N Engl J Med. 2002; 347: 589-600.

11 Kinoshita S, Yoshioka A, Park YD, Ishizashi H, Konno M, Funato M, Matsui T, Titani K, Yagi H, Matsumoto M, Fujimura Y. Upshaw-Schulman syndrome revisited: a concept of congenital thrombotic thrombocytopenic purpura. Int $J$ Hematol. 2001; 74: 101-8.

12 Fujimura Y, Matsumoto M, Kokame K, Isonishi A, Soejima K, Akiyama N, Tomiyama J, Natori K, Kuranishi Y, Imamura Y, Inoue N, Higasa S, Seike M, Kozuka T, Hara M, Wada H, Murata M, Ikeda Y, Miyata T, George JN. Pregnancy-induced thrombocytopenia and TTP, and the risk of fetal death, in Upshaw-Schulman syndrome: a series of 15 pregnancies in 9 genotyped patients. $\mathrm{Br}$ J Haematol. 2009; 144: 742-54.

13 Fujikawa K, Suzuki H, McMullen B, Chung D. Purification of human von Willebrand factor-cleaving protease and its identification as a new member of the metalloproteinase family. Blood. 2001; 98: 1662-6.

14 Gerritsen HE, Robles R, Lämmle B, Furlan M. Partial amino acid sequence of purified von Willebrand factor-cleaving protease. Blood. 2001; 98: 1654-61.

15 Tsai HM. Pathophysiology of thrombotic thrombocytopenic purpura. Int $J$ Hematol. 2010; 91: 1-19.

16 Fujimura Y, Matsumoto M. Registry of 919 patients with thrombotic microangiopathies across Japan: database of Nara Medical University during 1998-2008. Intern Med. 2010; 49: 7-15.

17 Dacie JV, Mollison PL, Richardson N, Selwyn JG, Shapiro L. Atypical congenital haemolytic anaemia. Q J Med. 1953; 22: 79-98.

18 Schulman I, Pierce M, Lukens A, Currimbhoy Z. Studies on thrombopoiesis. I. A factor in normal human plasma required for platelet production; chronic thrombocytopenia due to its deficiency. Blood. 1960; 16: 943-57.

19 Upshaw JD, Jr. Congenital deficiency of a factor in normal plasma that reverses microangiopathic hemolysis and thrombocytopenia. $N$ Engl J Med. 1978; 298: $1350-2$.

20 Rennard S, Abe S. Decreased cold-insoluble globulin in congenital thrombocytopenia (Upshaw-Schulman syndrome). N Engl J Med. 1979; 300: 368. 

Upshaw-Schulman syndrome and fibronectin (cold insoluble globulin). $N$ Engl $J$ Med. 1981; 305: 1284-5.

22 Goodnough LT, Saito H, Ratnoff OD. Fibronectin levels in congenital thrombocytopenia: Schulman's syndrome. N Engl J Med. 1982; 306: 938-9.

23 Miura M, Koizumi S, Miyazaki H. Thrombopoietin in Upshaw-Schulman syndrome. Blood. 1997; 89: 4663-4.

24 Moake JL, Rudy CK, Troll JH, Weinstein MJ, Colannino NM, Azocar J, Seder RH, Hong SL, Deykin D. Unusually large plasma factor VIII: von Willebrand factor multimers in chronic relapsing thrombotic thrombocytopenic purpura. $N$ Engl J Med. 1982; 307: 1432-5.

25 Furlan M, Robles R, Solenthaler M, Wassmer M, Sandoz P, Lämmle B. Deficient activity of von Willebrand factor-cleaving protease in chronic relapsing thrombotic thrombocytopenic purpura. Blood. 1997; 89: 3097-103.

26 Kokame K, Matsumoto M, Soejima K, Yagi H, Ishizashi H, Funato M, Tamai H, Konno M, Kamide K, Kawano Y, Miyata T, Fujimura Y. Mutations and common polymorphisms in ADAMTS13 gene responsible for von Willebrand factor-cleaving protease activity. Proc Natl Acad Sci U S A. 2002; 99: 11902-7.

27 Furlan M, Robles R, Lämmle B. Partial purification and characterization of a protease from human plasma cleaving von Willebrand factor to fragments produced by in vivo proteolysis. Blood. 1996; 87: 4223-34.

28 Kato S, Matsumoto M, Matsuyama T, Isonishi A, Hiura H, Fujimura Y. Novel monoclonal antibody-based enzyme immunoassay for determining plasma levels of ADAMTS13 activity. Transfusion. 2006; 46: 1444-52.

29 Kokame K, Nobe Y, Kokubo Y, Okayama A, Miyata T. FRETS-VWF73, a first fluorogenic substrate for ADAMTS13 assay. Br J Haematol. 2005; 129: 93-100. 30 Ferrari S, Mudde GC, Rieger M, Veyradier A, Kremer Hovinga JA, Scheiflinger F. IgG subclass distribution of anti-ADAMTS13 antibodies in patients with acquired thrombotic thrombocytopenic purpura. J Thromb Haemost. 2009; 7:1703-10.

31 Kokame K, Kokubo Y, Miyata T. Polymorphisms and mutations of ADAMTS13 in Japanese population and estimation of the number of patients with Upshaw-Schulman syndrome. J Thromb Haemost. (in press). 

Konetschny C, Antoine G, Rieger M, Scheiflinger F. Modulation of ADAMTS13 secretion and specific activity by a combination of common amino acid plymorphisms and a missense mutation. Blood. 2006; 107: 118-25.

33 Schettert IT, Pereira AC, Lopes NH, Hueb WA, Krieger JE. Association between ADAMTS13 polymorphisms and risk of cardiovascular events in chronic coronary disease. Thromb Res. 2010; 125: 61-6.

34 Ruan C, Dai L, Su J, Wang Z. The frequency of P475S polymorphism in von Willebrand factor-cleaving protease in the Chinese population and its relevance to arterial thrombotic disorders. Thromb Haemost. 2004; 91: 1257-8.

35 Bongers TN, De Maat MP, Dippel DW, Uitterlinden AG, Leebeek FW. Absence of Pro475Ser polymorphism in ADAMTS-13 in Caucasians. J Thromb Haemost. 2005; 3: 805.

36 Akiyama M, Kokame K, Miyata T. ADAMTS13 P475S polymorphism causes a lowered enzymatic activity and urea lability in vitro. $J$ Thromb Haemost. 2008; 6: 1830-2.

Yagi H, Konno M, Kinoshita S, Matsumoto M, Ishizashi H, Matsui T, Titani K, Fujimura Y. Plasma of patients with Upshaw-Schulman syndrome, a congenital deficiency of von Willebrand factor-cleaving protease activity, enhances the aggregation of normal platelets under high shear stress. Br J Haematol. 2001; 115: $991-7$.

38 Konno M, Yoshioka A, Takase T, Imai T. Partial clinical improvement in Upshaw-Schulman syndrome following prostacyclin infusion. Acta Paediatr Jpn. 1995; 37: 97-100.

39 Miura M, Koizumi S, Nakamura K, Ohno T, Tachinami T, Yamagami M, Taniguchi N, Kinoshita S, Abildgaard CF. Efficacy of several plasma components in a young boy with chronic thrombocytopenia and hemolytic anemia who responds repeatedly to normal plasma infusions. Am J Hematol. 1984; 17: 307-19.

40 Matsumoto M, Kokame K, Soejima K, Miura M, Hayashi S, Fujii Y, Iwai A, Ito E, Tsuji Y, Takeda-Shitaka M, Iwadate M, Umeyama H, Yagi H, Ishizashi H, Banno F, Nakagaki T, Miyata T, Fujimura Y. Molecular characterization of ADAMTS13 gene mutations in Japanese patients with Upshaw-Schulman syndrome. 
Blood. 2004; 103: 1305-10.

41 Shinohara T, Miyamura S, Suzuki E, Kobayashi K. Congenital microangiopathic hemolytic anemia: report of a Japanese girl. Eur J Pediatr. 1982; 138: $191-3$.

42 Uchida T, Wada H, Mizutani M, Iwashita M, Ishihara H, Shibano T, Suzuki M, Matsubara Y, Soejima K, Matsumoto M, Fujimura Y, Ikeda Y, Murata M. Identification of novel mutations in ADAMTS13 in an adult patient with congenital thrombotic thrombocytopenic purpura. Blood. 2004; 104: 2081-3.

43 Shibagaki Y, Matsumoto M, Kokame K, Ohba S, Miyata T, Fujimura Y, Fujita T. Novel compound heterozygote mutations (H234Q/R1206X) of the ADAMTS13 gene in an adult patient with Upshaw-Schulman syndrome showing predominant episodes of repeated acute renal failure. Nephrol Dial Transplant. 2006; 21: 1289-92.

44 Kato R, Shinohara A, Sato J. ADAMTS13 deficiency, an important cause of thrombocytopenia during pregnancy. Int J Obstet Anesth. 2009; 18: 73-7.

45 Kokame K, Aoyama Y, Matsumoto M, Fujimura Y, Miyata T. Inherited and de novo mutations of ADAMTS13 in a patient with Upshaw-Schulman syndrome. $J$ Thromb Haemost. 2008; 6: 213-5.

46 Saitoh H, Murakami H, Mori C. Upshaw-Schulman syndrome in two siblings. Acta Paediatr Jpn. 1990; 32: 373-6.

47 Hara T, Kitano A, Kajiwara T, Kondo T, Sakai K, Hamasaki Y. Factor VIII concentrate-responsive thrombocytopenia, hemolytic anemia, and nephropathy. Evidence that factor VIII:von Willebrand factor is involved in its pathogenesis. Am J Pediatr Hematol Oncol. 1986; 8: 324-8.

48 Sasahara Y, Kumaki S, Ohashi Y, Minegishi M, Kano H, Bessho F, Tsuchiya S. Deficient activity of von Willebrand factor-cleaving protease in patients with Upshaw-Schulman syndrome. Int J Hematol. 2001; 74: 109-14.

49 Kentouche K, Budde U, Furlan M, Scharfe V, Schneppenheim R, Zintl F. Remission of thrombotic thrombocytopenic purpura in a patient with compound heterozygous deficiency of von Willebrand factor-cleaving protease by infusion of solvent/detergent plasma. Acta Paediatr. 2002; 91: 1056-9.

50 Schneppenheim R, Budde U, Oyen F, Angerhaus D, Aumann V, Drewke E, Hassenpflug W, Haberle J, Kentouche K, Kohne E, Kurnik K, Mueller-Wiefel D, 
Obser T, Santer R, Sykora KW. von Willebrand factor cleaving protease and ADAMTS13 mutations in childhood TTP. Blood. 2003; 101: 1845-50.

51 Antoine G, Zimmermann K, Plaimauer B, Grillowitzer M, Studt JD, Lämmle B, Scheiflinger F. ADAMTS13 gene defects in two brothers with constitutional thrombotic thrombocytopenic purpura and normalization of von Willebrand factor-cleaving protease activity by recombinant human ADAMTS13. $\mathrm{Br}$ J Haematol. 2003; 120: 821-4.

52 Savasan S, Lee SK, Ginsburg D, Tsai HM. ADAMTS13 gene mutation in congenital thrombotic thrombocytopenic purpura with previously reported normal VWF cleaving protease activity. Blood. 2003; 101: 4449-51.

53 Assink K, Schiphorst R, Allford S, Karpman D, Etzioni A, Brichard B, van de Kar N, Monnens L, van den Heuvel L. Mutation analysis and clinical implications of von Willebrand factor-cleaving protease deficiency. Kidney Int. 2003; 63: 1995-9. 54 Pimanda JE, Maekawa A, Wind T, Paxton J, Chesterman CN, Hogg PJ. Congenital thrombotic thrombocytopenic purpura in association with a mutation in the second CUB domain of ADAMTS13. Blood. 2004; 103: 627-9.

55 Veyradier A, Lavergne JM, Ribba AS, Obert B, Loirat C, Meyer D, Girma JP. Ten candidate ADAMTS13 mutations in six French families with congenital thrombotic thrombocytopenic purpura (Upshaw-Schulman syndrome). J Thromb Haemost. 2004; 2: 424-9.

56 Licht C, Stapenhorst L, Simon T, Budde U, Schneppenheim R, Hoppe B. Two novel ADAMTS13 gene mutations in thrombotic thrombocytopenic purpura/hemolytic-uremic syndrome (TTP/HUS). Kidney Int. 2004; 66: 955-8.

57 Noris M, Bucchioni S, Galbusera M, Donadelli R, Bresin E, Castelletti F, Caprioli J, Brioschi S, Scheiflinger F, Remuzzi G. Complement factor H mutation in familial thrombotic thrombocytopenic purpura with ADAMTS13 deficiency and renal involvement. J Am Soc Nephrol. 2005; 16: 1177-83.

58 Tao Z, Anthony K, Peng Y, Choi H, Nolasco L, Rice L, Moake JL, Dong JF. Novel ADAMTS-13 mutations in an adult with delayed onset thrombotic thrombocytopenic purpura. J Thromb Haemost. 2006; 4: 1931-5.

59 Schneppenheim R, Kremer Hovinga JA, Becker T, Budde U, Karpman D, Brockhaus W, Hrachovinova I, Korczowski B, Oyen F, Rittich S, von Rosen J, Tjonnfjord GE, Pimanda JE, Wienker TF, Lämmle B. A common origin of the 
4143insA ADAMTS13 mutation. Thromb Haemost. 2006; 96: 3-6.

60 Donadelli R, Banterla F, Galbusera M, Capoferri C, Bucchioni S, Gastoldi S, Nosari S, Monteferrante G, Ruggeri ZM, Bresin E, Scheiflinger F, Rossi E, Martinez C, Coppo R, Remuzzi G, Noris M. In-vitro and in-vivo consequences of mutations in the von Willebrand factor cleaving protease ADAMTS13 in thrombotic thrombocytopenic purpura. Thromb Haemost. 2006; 96: 454-64.

61 Peyvandi F, Lavoretano S, Palla R, Valsecchi C, Merati G, De Cristofaro R, Rossi E, Mannuccio Mannucci P. Mechanisms of the interaction between two ADAMTS13 gene mutations leading to severe deficiency of enzymatic activity. Hum Mutat. 2006; 27: 330-6.

62 Manea M, Kristoffersson A, Tsai HM, Zhou W, Winqvist I, Oldaeus G, Billstrom R, Bjork P, Holmberg L, Karpman D. ADAMTS13 phenotype in plasma from normal individuals and patients with thrombotic thrombocytopenic purpura. Eur J Pediatr. 2007; 166: 249-57.

63 Hommais A, Rayes J, Houllier A, Obert B, Legendre P, Veyradier A, Girma JP, Ribba AS. Molecular characterization of four ADAMTS13 mutations responsible for congenital thrombotic thrombocytopenic purpura (Upshaw-Schulman syndrome). Thromb Haemost. 2007; 98: 593-9.

64 Meyer SC, Jeddi R, Meddeb B, Gouider E, Lammle B, Kremer Hovinga JA. A first case of congenital TTP on the African continent due to a new homozygous mutation in the catalytic domain of ADAMTS13. Ann Hematol. 2008; 87: 663-6.

65 Garagiola I, Valsecchi C, Lavoretano S, Oren H, Bohm M, Peyvandi F. Nonsense-mediated mRNA decay in the ADAMTS13 gene caused by a 29-nucleotide deletion. Haematologica. 2008; 93: 1678-85.

66 Cermakova Z, Hrdlikova R, Sulakova T, Koristka M, Kovarova P, Hrachovinova I. Thrombotic thrombocytopenic purpura: incidence of congenital form of disease in north Moravia (region Moravia-Silesia). Prague Med Rep. 2009; 110: $239-44$.

67 Ma E, Li Y, Kwok J, Ling S, Pau P, Chau G. ADAMTS13 mutationmal analysis in Chinese patients wtih chronic relapsing thrombotic thrombocytopenic purpura. HK J Paediatr. 2006; 11: 22-7.

68 Park HW, Oh D, Kim N, Cho HY, Moon KC, Chae JH, Ahn HS, Choi Y, Cheong HI. Congenital thrombotic thrombocytopenic purpura associated with 
unilateral moyamoya disease. Pediatr Nephrol. 2008; 23: 1555-8.

69 Furlan M, Lämmle B. Aetiology and pathogenesis of thrombotic thrombocytopenic purpura and haemolytic uraemic syndrome: the role of von Willebrand factor-cleaving protease. Best Pract Res Clin Haematol. 2001; 14: 437-54.

70 Bernardo A, Ball C, Nolasco L, Moake JF, Dong JF. Effects of inflammatory cytokines on the release and cleavage of the endothelial cell-derived ultralarge von Willebrand factor multimers under flow. Blood. 2004; 104: 100-6.

71 Motto DG, Chauhan AK, Zhu G, Homeister J, Lamb CB, Desch KC, Zhang W, Tsai HM, Wagner DD, Ginsburg D. Shigatoxin triggers thrombotic thrombocytopenic purpura in genetically susceptible ADAMTS13-deficient mice. $J$ Clin Invest. 2005; 115: 2752-61.

72 Banno F, Kokame K, Okuda T, Honda S, Miyata S, Kato H, Tomiyama Y, Miyata T. Complete deficiency in ADAMTS13 is prothrombotic, but it alone is not sufficient to cause thrombotic thrombocytopenic purpura. Blood. 2006; 107: 3161-6. 73 Ishizashi H, Yagi H, Matsumoto M, Soejima K, Nakagaki T, Fujimura Y. Quantitative Western blot analysis of plasma ADAMTS13 antigen in patients with Upshaw-Schulman syndrome. Thromb Res. 2007; 120: 381-6.

74 Stirling Y, Woolf L, North WR, Seghatchian MJ, Meade TW. Haemostasis in normal pregnancy. Thromb Haemost. 1984; 52: 176-82.

75 Sánchez-Luceros A, Farías CE, Amaral MM, Kempfer AC, Votta R, Marchese C, Salviú MJ, Woods AI, Meschengieser SS, Lazzari MA. von Willebrand factor-cleaving protease (ADAMTS13) activity in normal non-pregnant women, pregnant and post-delivery women. Thromb Haemost 2004; 92:1320-6. 


\section{Figure legend}

Figure 1. Geographical distribution of 43 Japanese patients with USS and their ADAMTS13 gene mutations.

Among 43 USS patients, an ADAMTS13 gene analysis was performed in 39 patients. Nine of the 39 USS patients had homozygous ADAMTS13 gene mutations, and 29 were the compound heterozygotes, including one patient (USS-W4: patient no 28) with disease-causing mutation (DCM) on one allele while the other was unidentified. In the remaining one patient (USS-X5: patient no 29), two single nucleotide polymorphisms (SNPs), p.P475S and p.G1181R, but not DCMs were identified on each allele. The p.Q449X mutation localized to the northern part (Tohoku) of Honshu, c.2259delA to Kyushu, p.C908Y to western Japan, and p.R193W to a relatively wide area across Japan. Circled numbers indicate the patients shown in Table 1 and 2. 
Fig. 1.

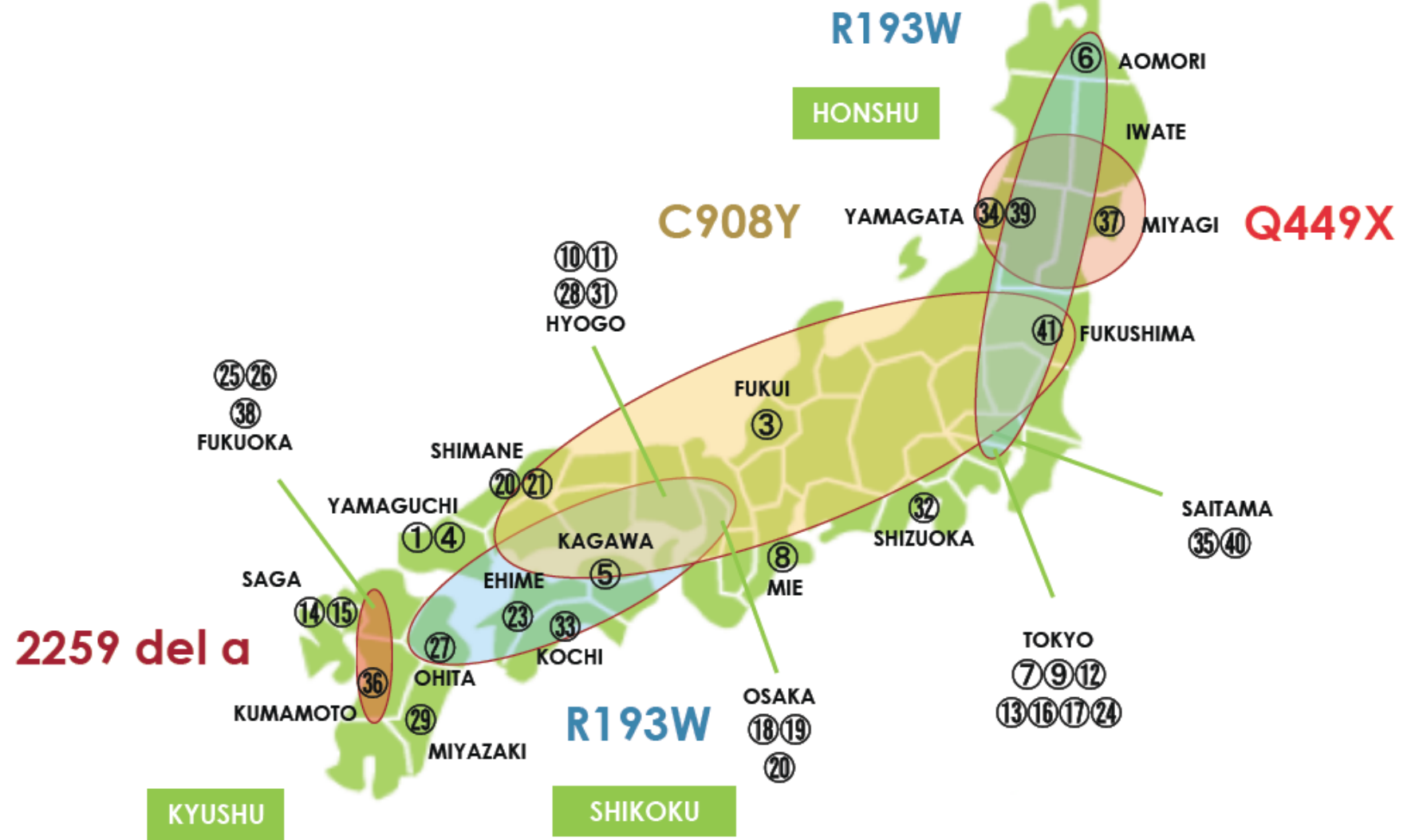


Table.1.

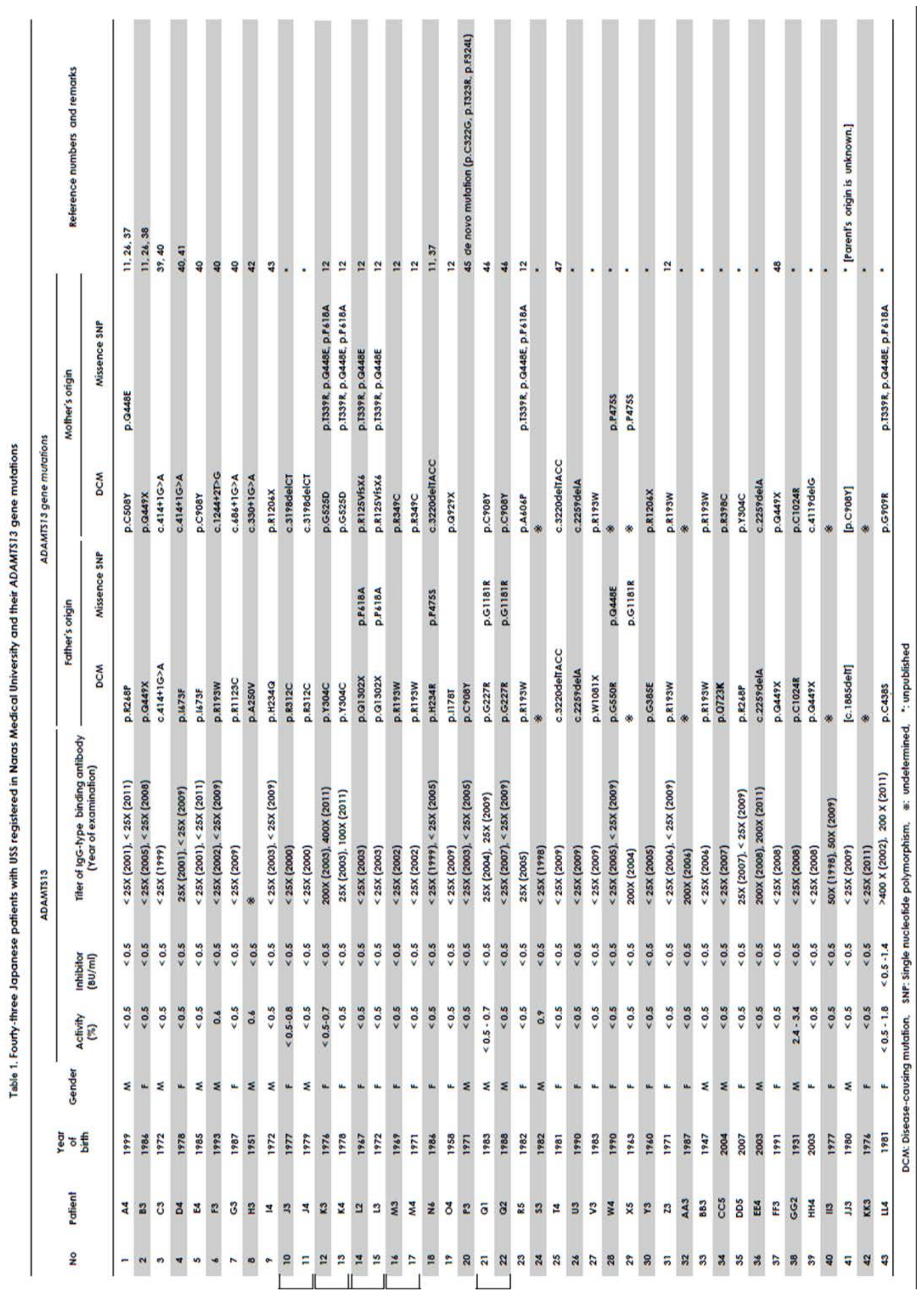


Table 2. Clinical course of 41 patients with Upshaw-Schulman syndrome (USS)

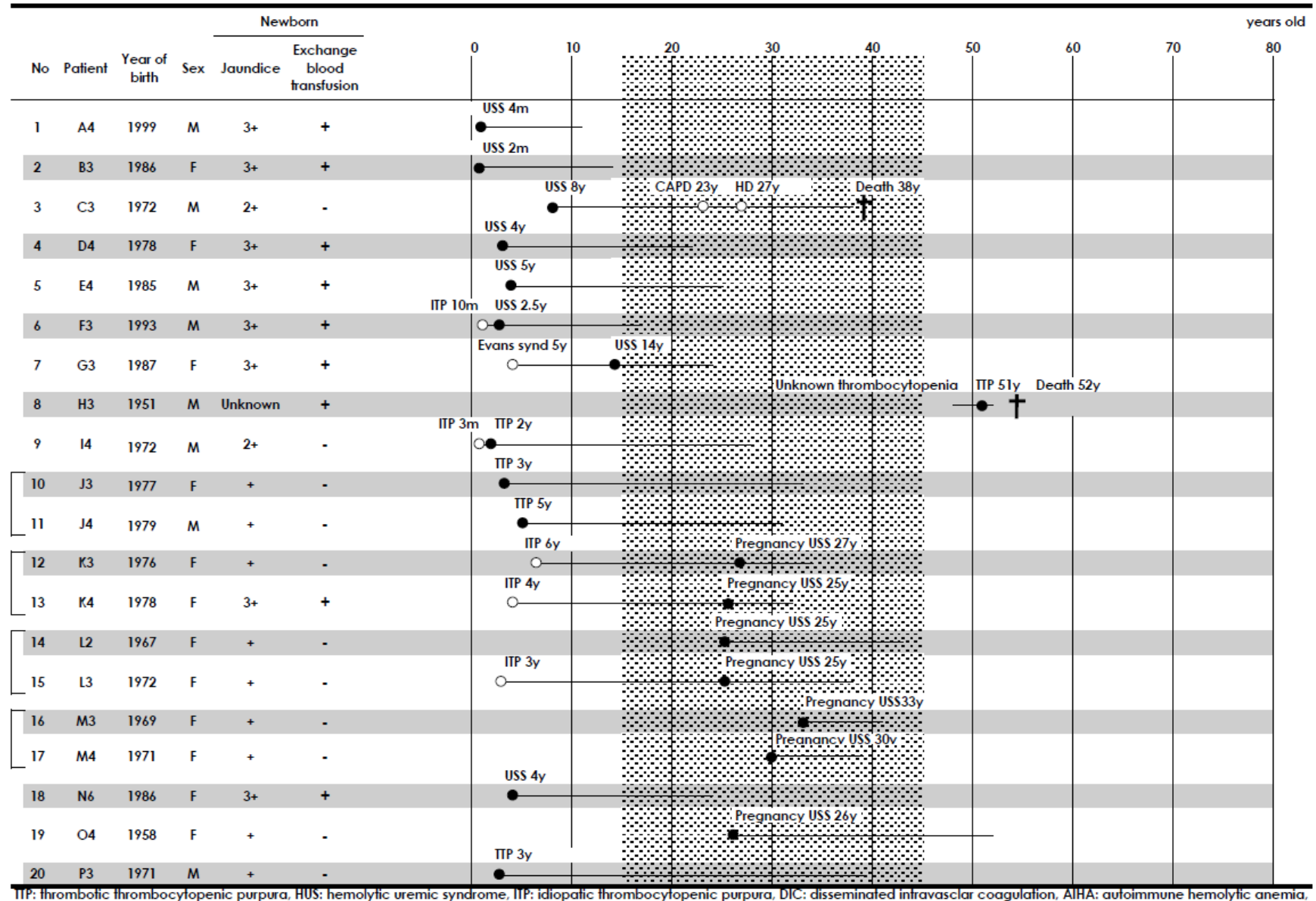

IIP: thrombotic thrombocytopenic purpura, HUS: $\mathrm{h}$
CAPD: continuous ambulatory peritoneal dialysis

Table 2 (continued)

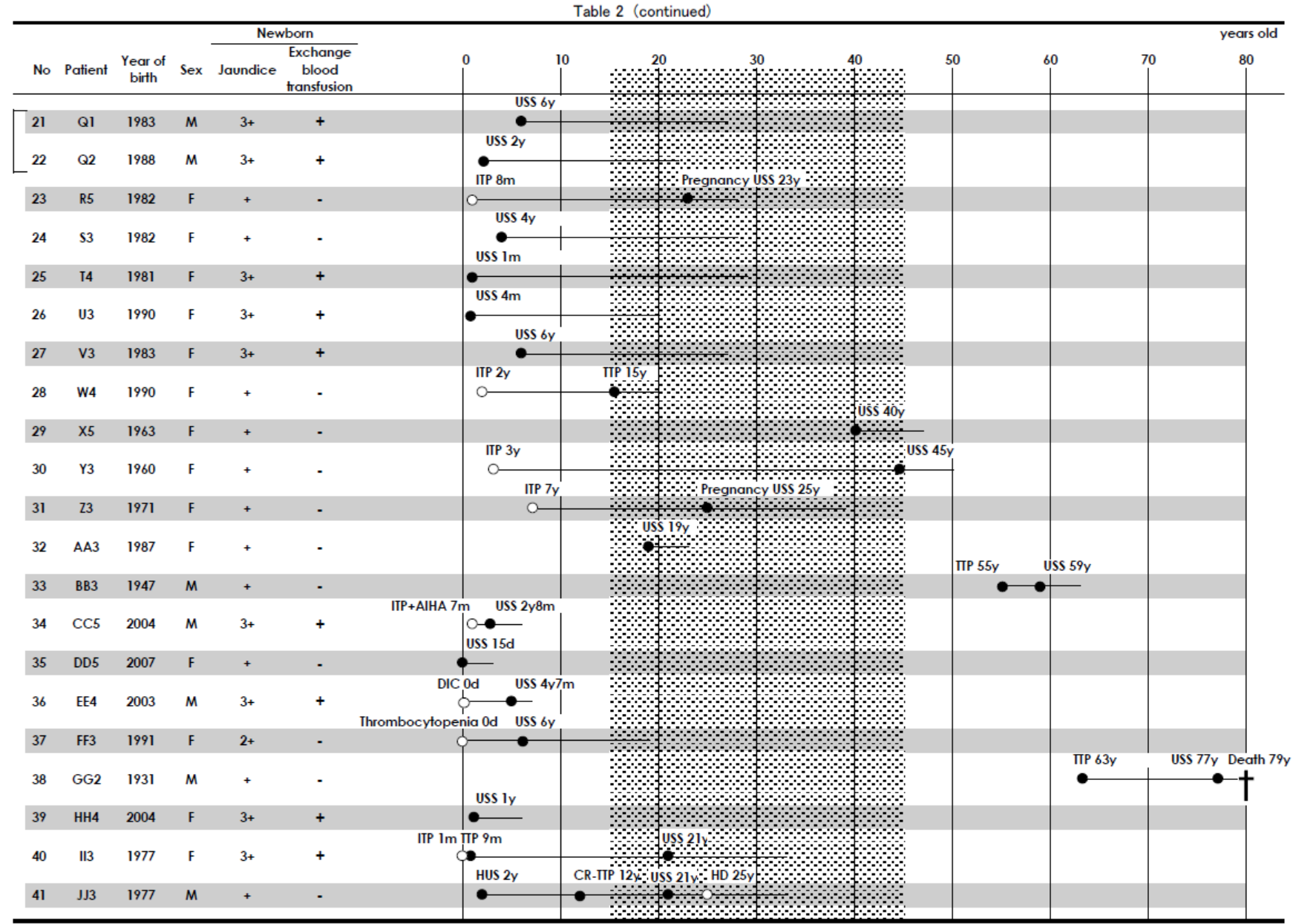


Table 3. Summary of 65 allelic numbers of ADAMTS13 disease-causing gene mutation out of 69 mutations in 35 Japanese patients with USS (5 siblings)

\begin{tabular}{ll}
\hline$\geq 2$ allelic numbers $(\mathrm{n}=11)$ \\
\hline & Allelic numbers \\
p.R193W & 8 \\
p.Q449X & 5 \\
p.C908Y & 4 \\
c.2259del A & 4 \\
c.414+1G>A & 3 \\
c.3220delTACC & 3 \\
p.R268P & 2 \\
p.Y304C & 2 \\
p.1673F & 2 \\
p.C1024R & 2 \\
p.R1206X & 2 \\
\hline
\end{tabular}

\begin{tabular}{ll}
\hline One allelic number $(\mathrm{n}=28)$ & \\
\hline p.I178T & p.A606P \\
p.G227R & p.Q723K \\
p.H234R & p.G909R \\
p.H234Q & p.Q929X \\
p.A250V & p.W1081X \\
p.R312C & p.R1123C \\
p.C322G/p.T323R/p.F324L & p.Q1302X \\
p.R349C & $c .372$ insGT \\
p.G385E & $c .1885$ delT \\
p.R398C & $c .3198 d e I C T$ \\
p.C438S & $c .4119$ delG \\
p.C508Y & $c .330+1 G>A$ \\
p.G525D & $c .686+1 G>A$ \\
p.G550R & $c .1244+2 T>G$ \\
\hline
\end{tabular}

